Article

\title{
Friction-Induced Vibration of a Railway Wheelset-Track System and Its Effect on Rail Corrugation
}

\section{Guangxiong Chen 1}

Tribology Research Institute, Southwest Jiaotong University, Chengdu 610031, China; chen_guangx@163.com

Received: 8 November 2019; Accepted: 23 December 2019; Published: 10 February 2020

check for updates

\begin{abstract}
In the present study, the effect of the radius of railway curved tracks on the slip of a wheel on a rail is studied. A 3D finite-element model of a wheelset-track system is established when the creep force between the wheel and rail is saturated. The occurrence propensity of the self-excited vibration of the wheelset-track system is predicted. It is concluded that the radius of curved tracks has a strong effect on the slip of wheels on rails. In the tightly curved tracks, the slip of the wheel of the leading wheelset on the rail always occurs. The wheelset-track system has a strong occurrence propensity for unstable vibrations on the tightly curved tracks. The accuracy of the rail corrugation prediction based on the unstable vibrations of wheelset-track systems is determined to be $85-90 \%$ or higher.
\end{abstract}

Keywords: friction-induced vibration; self-excited vibration; squeal; rail corrugation; wear

\section{Introduction}

\subsection{Background}

Rail corrugation refers to undulant wear on the running surface of rails as shown in Figure 1 [1-3]. When a vehicle passes through on a track with rail corrugation, severe vibration and noise of the wheelset-track system are excited, incurring passengers' complaints and damaging the vehicle and track components.

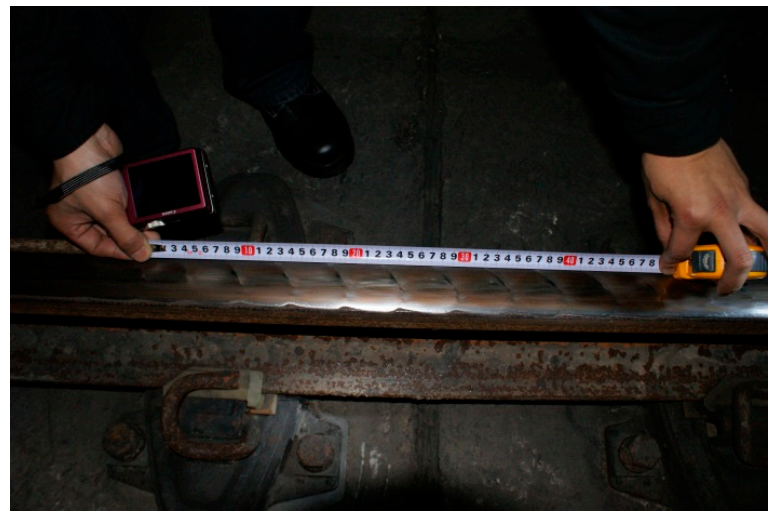

(a)

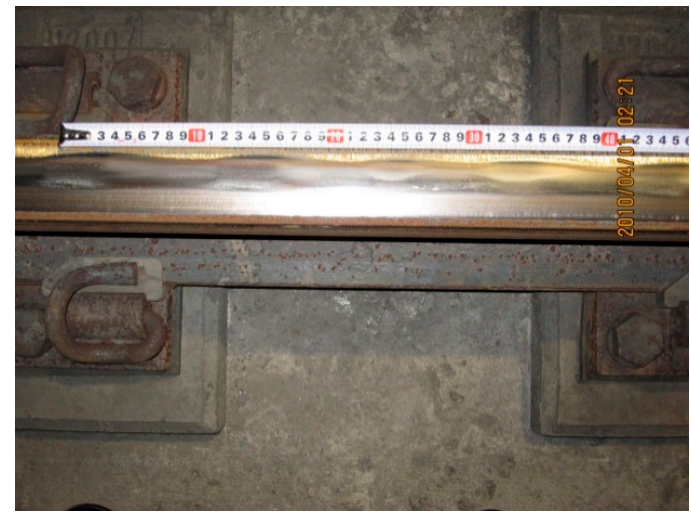

(b)

Figure 1. Photographs of rail corrugation: (a) corrugation on a rail supported by Colong-egg fasteners and $(\mathbf{b})$ corrugation on a rail supported by short sleepers. 
Railway tracks all over the world are subjected to rail corrugation to some extent. In the research field of rail corrugation, there is a very common and deterministic phenomenon of rail corrugation (the CD phenomenon of rail corrugation), namely, almost all low rails on tightly curved tracks with radii of less than $350 \mathrm{~m}$ in China suffer from rail corrugation, but high rails on the same curved track rarely suffer from rail corrugation. The rails on smoothly curved tracks with radii larger than $650-800 \mathrm{~m}$ or on straight tracks rarely suffer from rail corrugation. In China's metro tracks, the occurrence probability of rail corrugation on low rails of curved tracks of radius $350 \mathrm{~m}$ or smaller is close to $100 \%$. However, the occurrence probability of rail corrugation on high rails of the same curved tracks is less than 10-15\%. The occurrence probability of rail corrugation on rails on smoothly curved tracks with radii larger than $650-800$ m or on straight tracks is less than $5-10 \%$. In China's railway main-line tracks, the occurrence probability of rail corrugation on low rails of curved tracks of radius $350 \mathrm{~m}$ or smaller is close to $100 \%$. However, the occurrence probability of rail corrugation on high rails of the same curved tracks is less than 10-15\%. The occurrence probability of rail corrugation on rails on smoothly curved tracks with radii larger than $650-800 \mathrm{~m}$ or on straight tracks is less than $0.1-0.5 \%$.

The length of corrugated rails on tightly curved tracks accounts for $80-90 \%$ or more of the total length of all corrugated rails. To date, the occurrence probability of rail corrugation on low rails of tightly curved tracks is still close to $100 \%$ and practical remedies for rail corrugation are passive and include rail grinding, friction modifiers, and variation of the passage speed.

With the development of world economies, numerous cities are adopting metro transportation as a solution to crowded city traffic. Because of the inevitable tightly curved tracks in metro lines, almost all metro tracks suffer from rail corrugation. Hence, rail corrugation is an urgent problem needing to be solved.

\subsection{Formulation of the Interest Problem}

Rail corrugation and brake squealing are two difficult problems with a one-hundred-year history. Brake squealing is still an elusive problem in the automobile industry [4-6]. Similarly, rail corrugation is also an elusive problem in the railway industry. It is well known that the root causes of rail corrugation and brake squealing are vibrations [1-3]. Brake squealing is due to a self-excited vibration while rail corrugation is due to roughness-excited vibration or stick-slip vibration. From the author's viewpoint, if rail corrugation is really due to a known external-excited vibration the problem has already been solved for a long time. In fact, rail corrugation has been an issue for over one hundred years. Combining this and the CD phenomenon of rail corrugation, the author considers that the problem can probably be attributed to self-excited vibration of the wheelset-track system.

Curve squealing, a type of squealing noise which is emitted by the wheel-rail system while a railway vehicle negotiates a tightly curved track, is well-known in the railway community [7]. It is generally accepted that the curve squeal is caused by the self-excited vibration of wheel-rail systems [8]. The curve squeal is an academic term, which refers, in particular, to the squealing noises whose frequency is located in the range 1000-20,000 Hz. In fact, friction can also cause a $20-1000 \mathrm{~Hz}$ self-excited vibration of the wheelset-track system. For example, the stick-slip vibration of wheel-rail systems has been extensively studied and is probably responsible for curve squealing and rail corrugation. Over the years, the author has studied squealing and thinks that the reason why brake squealing is difficult to solve is that the squeal is a noise emitted by self-excited vibration. Differently from the external-excited vibration, the excitation source of the self-excited vibration cannot be seen and measured. Nowadays, rail corrugation is also a difficult issue to solve. Similarly, the author thinks that rail corrugation can probably be attributed to self-excited vibration of the wheelset-track system.

\subsection{Literature Survey}

Many researchers, including Grassie [1], Johnson [9], Knothe [10], Nielsen [11], Vadillo [12], Meehan [13], Thompson [14], Jin [15], and so on, have made outstanding contributions to the resolution of the rail corrugation problem. The theoretical framework of rail corrugation has been established and 
includes the wavelength fixing mechanism and material removal mechanism [1-3]. The wavelength fixing mechanism explains what determines the wavelength of rail corrugation. The material removal mechanism explains which out of wear or plastic deformation creates the corrugated damage of rails. Nowadays, the material removal mechanism of rail corrugation is mainly attributed to wear in metro tracks. Most research works focus on the wavelength fixing mechanism. The vibration due to the interaction between the wheel and rail with random surface roughness [16-29] and vibration due to the stick-slip motion of the wheel-rail system [30-36] are considered to be the two main wavelength fixing mechanisms. In the literature, about $70 \%$ or more of publications are associated with the wavelength fixing mechanism of the interaction between the wheel and rail with random surface roughness. In spite of numerous researchers' endeavors and understandings of rail corrugation, the occurrence probability of rail corrugation on low rails of tightly curved tracks is still close to $100 \%$ and the suppression of rail corrugation is not as good as expected. According to the CD phenomenon of rail corrugation, the occurrence of rail corrugation is strongly dependent on the radius of tracks. However, the existing mainstream theory of rail corrugation does not include the effect of the radius of tracks; the radius of curved tracks is not considered as an input parameter in the models of rail corrugation.

\subsection{Scope and Contribution of This Study}

In the present study, a self-excited vibration theory of squealing noise is used to study rail corrugation. The slip of wheels on rails is correlated with rail corrugation. Vehicle curve negotiation is analyzed to see whether slip of wheels on rails occurs or not. A self-excited vibration model of the wheelset-track system, including a wheelset, two rails, and a series of sleepers, is established and analyzed. The results show that when the creep force between the wheel and rail is saturated, friction easily brings about the self-excited vibration of the wheelset-track system, which is most likely to be the generation cause of rail corrugation.

The author's aim is to emphasize the strong correlation between the rail corrugation and slip of wheels on rails, and to extend the study subject of squealing vibration to attract more researchers' interests.

\subsection{Organization of the Paper}

In the present paper, firstly, the similarity between the brake squeal and rail corrugation is presented in Section 1. The slip of a wheel on a rail is analyzed in Section 2. A self-excited vibration model of the wheelset-track system is established. The occurrence conditions of the self-excited vibration are analyzed in Section 3. Finally, several conclusions are drawn at the end of the paper.

\section{Slip of a Wheel on a Rail}

\subsection{Slip of a Wheel on a Rail}

Under most conditions, the slip of a wheel on a rail does not occur. Under these circumstances, the creep force between the wheel and rail is not saturated. Under some extreme conditions, however, the creep force between the wheel and rail is saturated, that is, it is equal to the friction force. For example, when a vehicle negotiates a tightly curved track, the creep force between the wheel of the leading wheelset of each bogie and rail is always saturated. Whether the creep force is saturated or not mainly depends on the radius of the tracks. Many scholars have studied vehicle system dynamics [37-39]. The author compiled a Fortran program for vehicle curve negotiation in his master's thesis and found that the creep force between the wheel and rail was always saturated on tightly curved tracks. In the present study, commercial SIMPACK software was used to establish a multi-body model of vehicle curve negotiation. The parameters of the model for a metro vehicle curve negotiation are presented in Table 1. 
Table 1. Main parameters of the model.

\begin{tabular}{|c|c|}
\hline Track & \\
\hline Density of rail $\left(\mathrm{kg} / \mathrm{m}^{3}\right)$ & 7800 \\
\hline Young's modulus of rail $\left(\mathrm{N} / \mathrm{m}^{2}\right)$ & $2.1 \times 10^{11}$ \\
\hline Poisson's ratio of rail & 0.3 \\
\hline Length of rail (m) & 36 \\
\hline Type of rail $(\mathrm{kg} / \mathrm{m})$ & 60 \\
\hline Sleeper spacing $(\mathrm{m})$ & 0.625 \\
\hline Rail cant & $1 / 40$ \\
\hline Density of railpad $\left(\mathrm{kg} / \mathrm{m}^{3}\right)$ & 1300 \\
\hline Young's modulus of railpad $\left(\mathrm{N} / \mathrm{m}^{2}\right)$ & $8.0 \times 10^{7}$ \\
\hline Poisson's ratio & 0.45 \\
\hline Thickness of railpad (m) & 0.012 \\
\hline Density of sleeper $\left(\mathrm{kg} / \mathrm{m}^{3}\right)$ & 2480 \\
\hline Young's modulus of sleeper $\left(\mathrm{N} / \mathrm{m}^{2}\right)$ & $1.9 \times 10^{11}$ \\
\hline Poisson's ratio of sleeper & 0.3 \\
\hline Vertical support stiffness from & \\
\hline monolithic track-bed $(\mathrm{N} / \mathrm{m})$ & $8.9 \times 10^{7}$ \\
\hline Vertical support damping from & \\
\hline monolithic track-bed (Ns/m) & $8.98 \times 10^{4}$ \\
\hline $\begin{array}{l}\text { Lateral support stiffness from } \\
\text { monolithic track-bed }(\mathrm{N} / \mathrm{m})\end{array}$ & $5.0 \times 10^{7}$ \\
\hline Lateral support damping from & \\
\hline $\begin{array}{l}\text { monolithic track-bed (Ns/m) } \\
\text { Vehicle }\end{array}$ & $4.0 \times 10^{4}$ \\
\hline Gauge $(\mathrm{mm})$ & 1435 \\
\hline Wheelbase of bogie (mm) & 2300 \\
\hline Profile of tread & LM-type worn profile \\
\hline Mass of wheelset (kg) & 1365 \\
\hline $\begin{array}{l}\text { Moment of inertia of wheelset in } \\
\text { vertical and lateral axes }\left(\mathrm{kg} \mathrm{m}^{2}\right)\end{array}$ & 880 \\
\hline $\begin{array}{l}\text { Moment of inertia of wheelset in } \\
\text { rolling axis }\left(\mathrm{kg} \mathrm{m}^{2}\right)\end{array}$ & 116 \\
\hline Mass of bogie $(\mathrm{kg})$ & 2028 \\
\hline Moment of inertia of bogie in & \\
\hline longitudinal level axes (kg m²) & 983 \\
\hline Moment of inertia of bogie in & \\
\hline lateral level axes $\left(\mathrm{kg} \mathrm{m}^{2}\right)$ & 582 \\
\hline $\begin{array}{l}\text { Moment of inertia of bogie in } \\
\text { vertical axes }\left(\mathrm{kg} \mathrm{m}^{2}\right)\end{array}$ & 1506 \\
\hline Mass of car body (kg) & 35,030 \\
\hline Moment of inertia of car body in & \\
\hline longitudinal level axes $\left(\mathrm{kg} \mathrm{m}^{2}\right)$ & 50,370 \\
\hline $\begin{array}{l}\text { Moment of inertia of car body in } \\
\text { the lateral level axes }\left(\mathrm{kg} \mathrm{m}^{2}\right)\end{array}$ & $1,395,430$ \\
\hline $\begin{array}{l}\text { Moment of inertia of car body in } \\
\text { vertical axes }\left(\mathrm{kg} \mathrm{m}^{2}\right)\end{array}$ & $1,386,060$ \\
\hline $\begin{array}{l}\text { Longitudinal stiffness of } \\
\text { primary suspension alone }(\mathrm{kN} / \mathrm{m})\end{array}$ & 4850 \\
\hline $\begin{array}{l}\text { Lateral stiffness of } \\
\text { primary suspension alone }(\mathrm{kN} / \mathrm{m})\end{array}$ & 3430 \\
\hline $\begin{array}{l}\text { Vertical stiffness of } \\
\text { primary suspension alone }(\mathrm{kN} / \mathrm{m})\end{array}$ & 740 \\
\hline $\begin{array}{l}\text { Vertical damping of } \\
\text { primary suspension alone }(\mathrm{kNs} / \mathrm{m})\end{array}$ & 15.626 \\
\hline $\begin{array}{l}\text { Vertical stiffness of } \\
\text { secondary suspension alone }(\mathrm{kN} / \mathrm{m})\end{array}$ & 480 \\
\hline $\begin{array}{l}\text { Lateral stiffness of } \\
\text { secondary suspension alone }(\mathrm{kN} / \mathrm{m})\end{array}$ & 210 \\
\hline $\begin{array}{l}\text { Vertical damping of } \\
\text { secondary suspension alone }(\mathrm{kNs} / \mathrm{m})\end{array}$ & 50 \\
\hline
\end{tabular}


Figures 2-5 show comparisons between the resultant creep force and friction force when the vehicle negotiates curved tracks. From Figure 2a it can be seen that the creep force between the inner wheel of the leading wheelset of each bogie and low rail is saturated and that the creep force between the outer wheel of the leading wheelset of each bogie and high rail is approximately saturated when the vehicle negotiates a curved track of radius $250 \mathrm{~m}$. It should be noted that since SIMPACK only obtained the numerical solution of the vehicle curve negotiation, not the analytical solution, there is always an error between the numerical and analytical solutions. In Figures 2-5, the resultant creep force is not exactly equal to the friction force. The author assumes that if the relative error between the resultant creep force and friction force is less than $5 \%$, the creep force is considered to be saturated. It can also be also seen that the creep force between the inner wheel of the leading wheelset of each bogie and low rail is not saturated clearly when the vehicle negotiates a curved track of radius $600 \mathrm{~m}$. From Figures 2-5, it can be concluded that the creep force between the wheel and low rail changes from a saturated state to an unsaturated state with increasing radius of curved tracks.

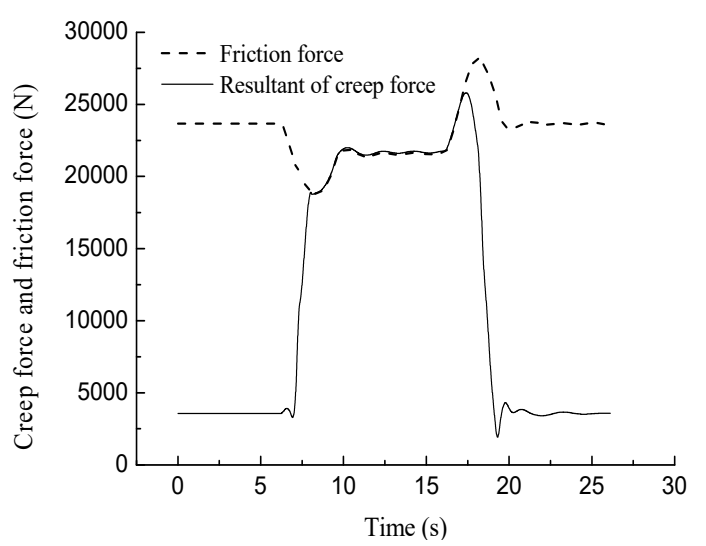

(a)

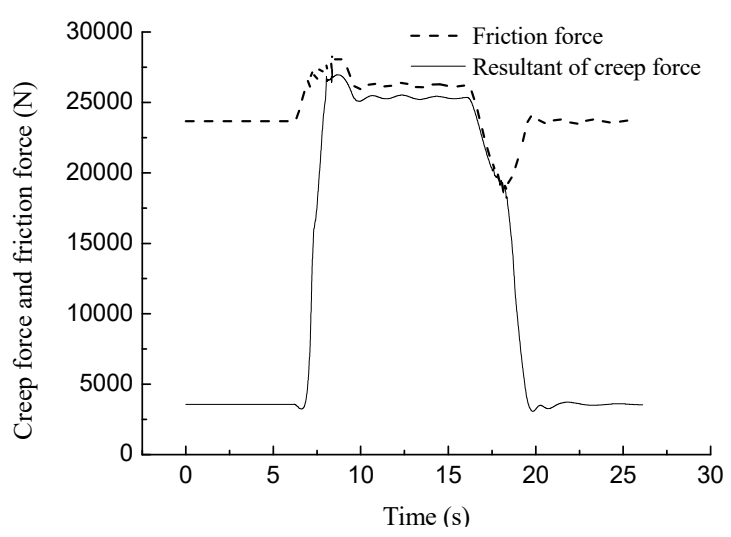

(b)

Figure 2. Comparison between the resultant creep force and friction force, $R=250 \mathrm{~m}$ (a) for low rail, relative error $\gamma=0.48 \%$ and (b) for high rail, $\gamma=3.34 \%$.

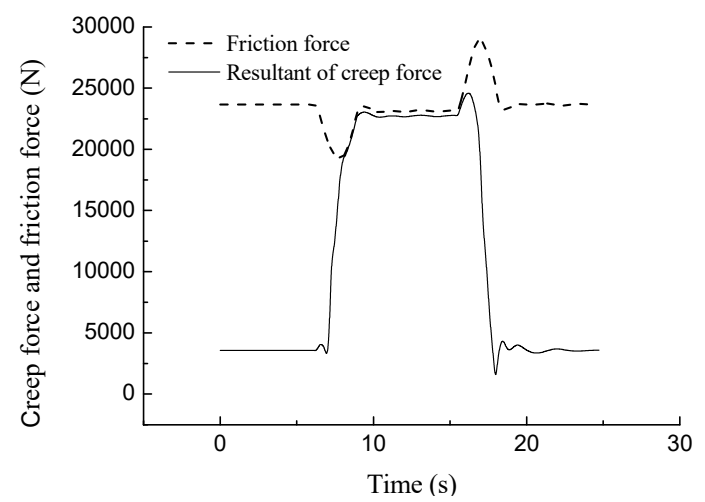

(a)

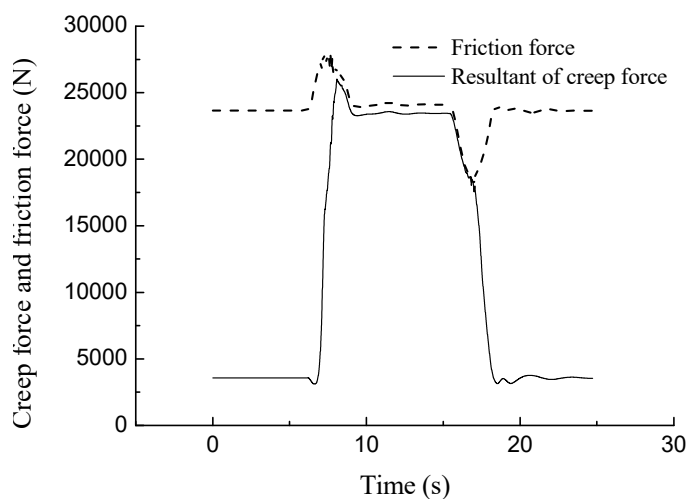

(b)

Figure 3. Comparison between the resultant creep force and friction force, $R=350 \mathrm{~m}$ (a) for low rail, $\gamma=1.81 \%$ and $(\mathbf{b})$ for high rail, $\gamma=2.68 \%$. 


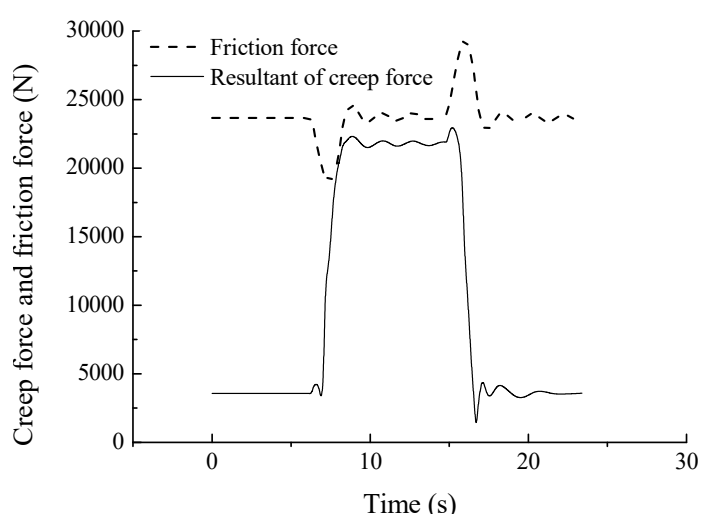

(a)

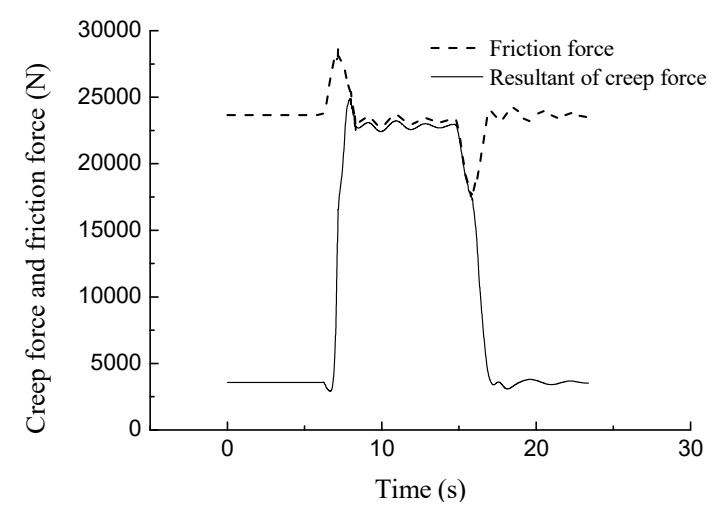

(b)

Figure 4. Comparison between the resultant creep force and the friction force, $R=450 \mathrm{~m}(\mathbf{a})$ for low rail, $\gamma=9.12 \%$ and (b) for high rail, $\gamma=1.87 \%$.

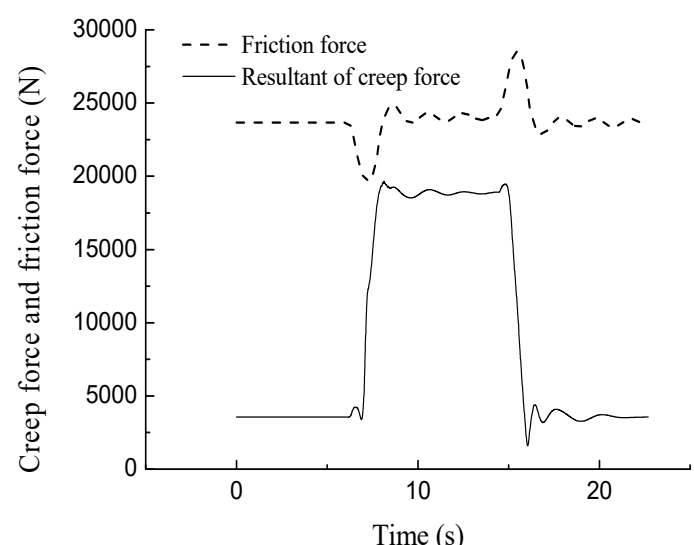

(a)

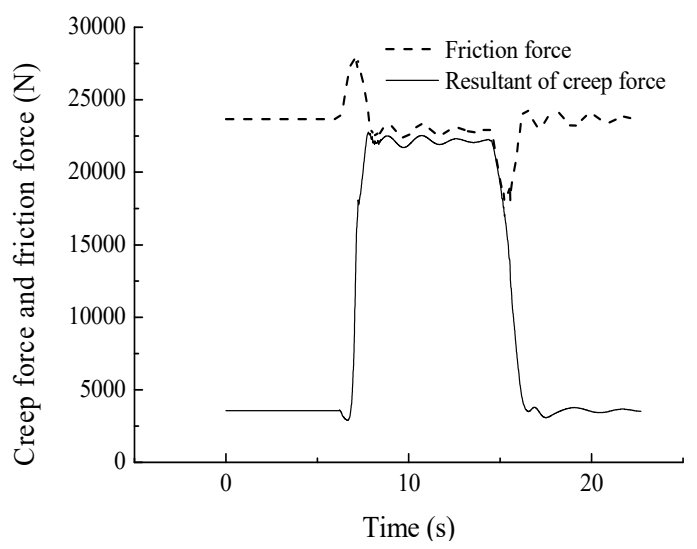

(b)

Figure 5. Comparison between the resultant creep force and friction force, $R=600 \mathrm{~m}$ (a) for low rail, $\gamma=21.46 \%$ and (b) for high rail, $\gamma=3.16 \%$.

\subsection{Correlation between Rail Corrugation and Slip of the Wheel on the Rail}

It is a well-known fact that the occurrence of brake squealing has a degree of uncertainty. According to the author's test experiences, the squeal occurrence of an automobile disc brake system has uncertainty, that is, sometimes the squeal occurs but sometimes the squeal does not occur when the nominal parameters are kept unchanged. However, the author also found that a metal sliding was always able to emit a squeal [40]. The author assumes that the occurrence of the squeal depends, to some extent, on the material compositions of the friction couple and the structures of the friction system.

Similarly, the author believes that there is a strong correlation between the rail corrugation and slip of the wheel on the rail. According to the $\mathrm{CD}$ phenomenon of rail corrugation, the occurrence probability of corrugation on the low rail of tightly curved tracks is very close to $100 \%$. Based on the results shown in Figures 2-5, it can be observed that on the tightly curved tracks, the inner wheel of the leading wheelset always slips on the low rail. From Figure 5 it can be seen that the inner wheel will not slip on the low rail when the radius of the curved tracks is equal to or larger than $600 \mathrm{~m}$. According to the $\mathrm{CD}$ phenomenon of rail corrugation, the occurrence probability of corrugation on rails of large-radius curved tracks is very low, being less than $5-10 \%$. Hence, the author considers that there is a strong correlation between the rail corrugation and slip of the wheel on the rail. The question may be raised regarding how to explain a $5-10 \%$ occurrence probability of corrugation on rails with large-radius curved tracks. The author's field investigations show that the $5-10 \%$ occurrence probability of corrugation on rails with large-radius curved tracks is still due to the slip of the wheel 
on the rail. Liu [33] reported that rail corrugation occurred on the low rail of a metro curved track of radius $700 \mathrm{~m}$ when a brake application was applied and that rail corrugation disappeared on the ground low rail of the same metro curved track when no brake application was applied. Liu concluded that the slip of the wheel on the rail due to the brake brought about rail corrugation.

\section{Squealing Vibration of a Wheelset-Track System}

\subsection{Model of the Squealing Vibration of a Wheelset-Track System}

Saulot and Baillet established a 2D finite-element model of a wheel-rail system in order to study its vibrational behavior and the correlation between behavior and rail corrugation [33]. Combining knowledge of friction-induced vibration and knowledge of vehicle system dynamics, Chen and other co-authors proposed a friction-induced self-excited vibration of a wheelset-track system as a possible mechanism for rail corrugation [34]. In a tightly curved track, the creep force between the wheel and rail is approximately equal to the friction force, that is, the normal force times the coefficient of friction. The motion equation of the wheelset-track system can be written as [34]

$$
M_{\mathrm{r}} \ddot{x}+C_{\mathrm{r}} \dot{x}+K_{\mathrm{r}} x=0
$$

where $M_{\mathrm{r}}, C_{\mathrm{r}}$, and $K_{\mathrm{r}}$ are the asymmetric matrices due to friction. The eigenvalue equation of Equation (1) can be presented as

$$
\left(M_{\mathrm{r}} \lambda^{2}+C_{\mathrm{r}} \lambda+K_{\mathrm{r}}\right) \phi=0
$$

The general solution of Equation (1) can be written as

$$
x(t)=\sum \phi_{\mathrm{i}} \exp \left(\lambda_{\mathrm{i}} t\right)=\sum \phi_{\mathrm{i}} \exp \left(\left(\alpha_{\mathrm{i}}+\mathrm{j} \omega_{\mathrm{i}}\right) t\right)
$$

where $\phi_{\mathrm{i}}$ is the ith eigenvector of Equation (2), $\lambda_{\mathrm{i}}=\alpha_{\mathrm{i}}+\mathrm{j} \omega_{\mathrm{i}}$ is the ith eigenvalue of Equation (2), and $j$ is the imaginary unit. From Equation (3) it can be seen that when a real part of the eigenvalues is larger than zero, the displacement will increase with time, that is, the vibration of the system becomes unstable.

Figure 6 shows a finite element model of a wheelset-track system which consists of a wheelset, two rails, and a series of sleepers. Nowadays, some commercial finite element packages provide the complex eigenvalue analysis ability of friction-induced self-excited vibration. The main procedures for applying ABAQUS to perform complex eigenvalue analysis of the wheelset-track system are given below.

(1) Step 1: nonlinear static analysis for applying axle-box forces.

(2) Step 2: nonlinear static analysis to impose the transversal sliding speed on the wheelset.

(3) Step 3: normal mode analysis to extract natural frequencies of the undamped system.

(4) Step 4: complex eigenvalue analysis that incorporates the effect of friction coupling.

The main source code of the prediction model was presented in Appendix A. The source code of the author's prediction model is open to researchers. 


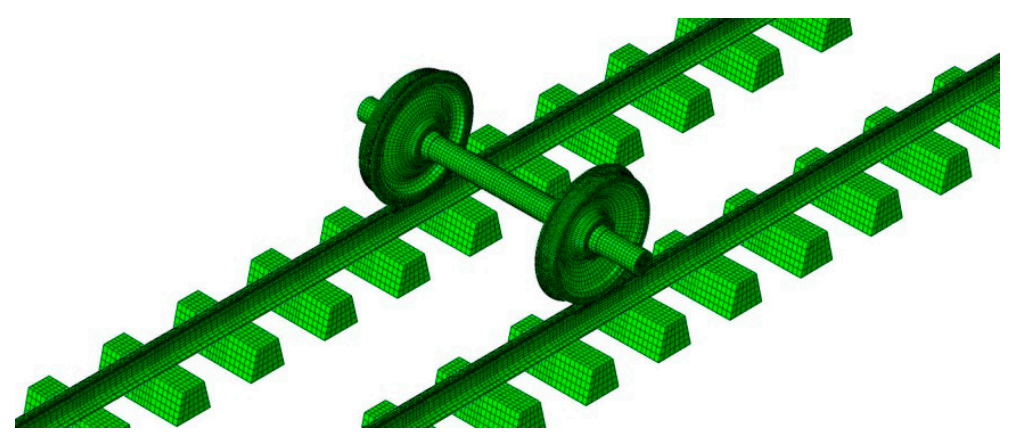

(a)

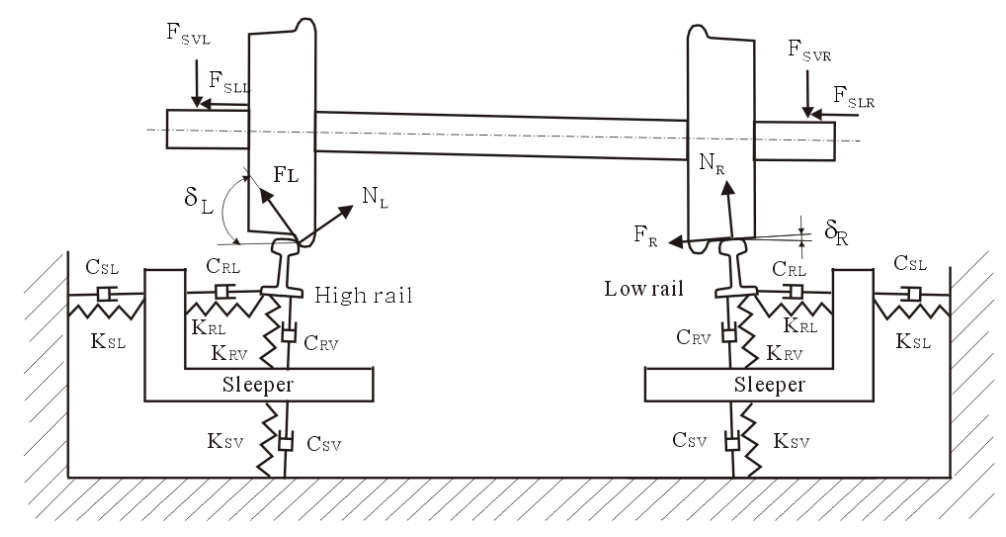

(b)

Figure 6. Finite element model of the wheelset-track system on a tightly curved track: (a) finite element model and (b) wheel-rail contacts. In the Figure, $N_{\mathrm{L}}$ and $N_{\mathrm{R}}$ represent normal contact forces. $F_{\mathrm{L}}$ and $F_{\mathrm{R}}$ stand for lateral creep forces. $\delta_{\mathrm{L}}$ and $\delta_{\mathrm{R}}$ represent contact angles. $K_{\mathrm{RL}}$ and $C_{\mathrm{RL}}$ represent lateral stiffness and damping of a single fastener. $K_{\mathrm{RV}}$ and $C_{\mathrm{RV}}$ stand for vertical stiffness and damping of a single fastener. $K_{\mathrm{SL}}$ and $C_{\mathrm{SL}}$ represent lateral support stiffness and damping of the subgrade. $K_{\mathrm{SV}}$ and $\mathrm{C}_{\mathrm{SV}}$ stand for vertical support stiffness and damping of the subgrade.

\subsection{Prediction Result of Squealing Vibration of the Wheelset-Track System}

In Section 2.1 it was seen that when the vehicle negotiates a tightly curved track, the creep forces between the wheels and rails are always saturated, that is, equal to the normal force multiplied by the coefficient of friction. For the wheelset-track system shown in Figure 6, when the slip of the wheels on rails is imposed, an occurrence tendency of the squealing vibration of the wheelset-track system is produced, as shown in Figure 7. It can be seen that there are several unstable vibrations when the coefficient of friction between the wheel and rail is equal to 0.45 . Figure 8 shows the mode shape of an unstable vibration. It is found that only the inner wheel and low rail are subjected to unstable vibration but that the outer wheel and high rail are not. The prediction result shown in Figure 8 is consistent with the field results of rail corrugation. As mentioned in the CD phenomenon of rail corrugation, in the field, the low rail is always subjected to corrugation but the high rail is seldom subjected to corrugation. 


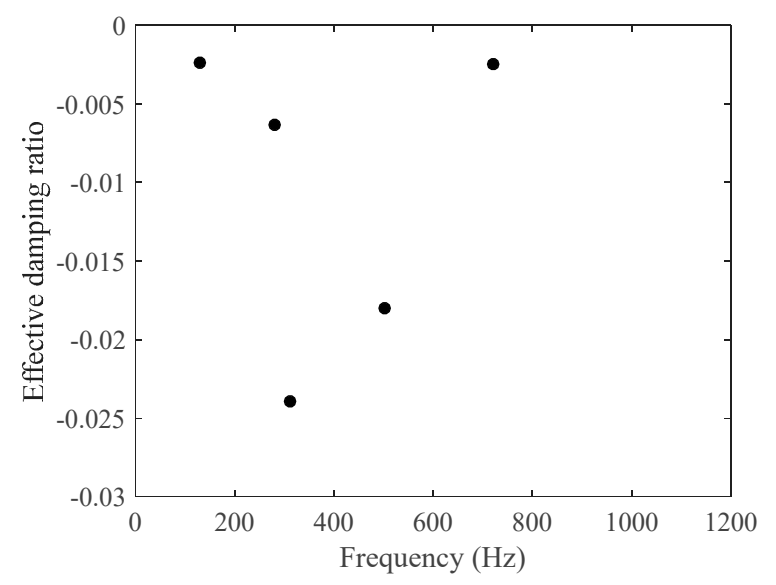

Figure 7. Distribution of unstable vibrations.

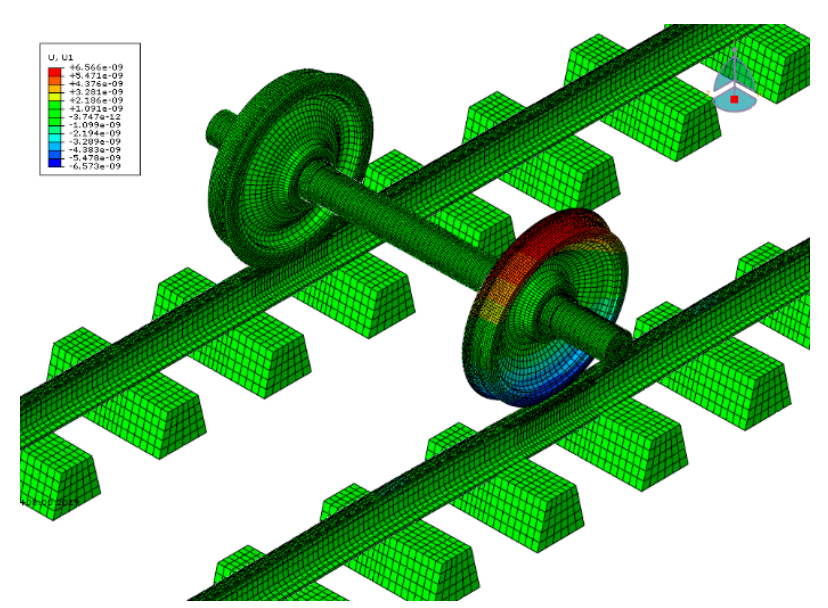

Figure 8. Mode shape of an unstable vibration of frequency $332.82 \mathrm{~Hz}$.

\subsection{Field Measurement of the Squealing Vibration of the Wheelset-Track System}

Measurements of curve squealing have been reported but the measurement of the squealing vibration of the wheelset-track system has been seldom reported in the literature. Cui et al. [29] reported a measurement of rail vibration and speculated that there was a squealing vibration in the rail vibration signal.

\subsection{Correlation between the Rail Corrugation and the Squealing Vibration of the Wheelset-Track System}

In this section the self-excited vibration of the wheelset-track system is correlated with corrugation generation. In the literature it is generally accepted that fluctuating friction work results in undulant wear of rails. Brockley [30] proposed a modified wear equation, i.e.,

$$
w=K(H-C)
$$

where $w$ is the wear volume per unit of time, $K$ is the wear constant, $H$ is the friction work rate (equals $F V), F$ is the creep force, $V$ is the relative velocity, and $C$ is the durability friction work rate. When the creep force $F$ is saturated, $F=u N$, where $u$ is the friction coefficient between the wheel and rail and $N$ is the normal contact force. In the present study, it is accepted that the normal contact force fluctuates when the self-excited vibration occurs. Therefore, it is deduced that the friction work rate $H$ fluctuates when the self-excited vibration occurs. According to Brockley [30], such a fluctuating friction work rate can cause rail corrugation. Hence, the self-excited vibration of the wheelset-track system is a possible wavelength-fixing mechanism. 
The author found it interesting that in the tightly curved tracks which have been designed based on existing design specifications, $0-1000 \mathrm{~Hz}$ unstable vibrations of the wheelset-track system are always predicted without any difficulty, as shown in Figure 7, and these unstable vibrations are difficult to remove by changing the superelevation, rail cant, stiffness and damping of fasteners, sleeper space, hardness of rails, and so on. This result suggests that rail corrugation on tightly curved tracks is difficult to solve. This is indeed true in actual tight metro tracks. In China's tight metro tracks, corrugations on low rails always occur with a short or long service time. No unstable vibration of the wheelset-track system arises on a curved track of radius $650 \mathrm{~m}$ and a tangential track since the creep forces between the wheels and rails are not saturated. This result suggests that the occurrence of rail corrugation on smoothly curved tracks whose radii are larger than 650-800 m or on tangential tracks is difficult. This is indeed true in actual tight metro tracks all over the world.

The author found it very interesting that if 50-1000 Hz unstable vibrations of the wheelset-track system are predicted, rail corrugation is more likely to occur on the rail of the wheelset-track system. Otherwise, corrugation seldom occurs. The accuracy of the rail corrugation prediction based on the unstable vibrations of wheelset-track systems is found to be $85-90 \%$ or higher.

\section{Simple Validation of the Prediction Model of Rail Corrugation}

Most recently, the author has discussed the validation of the prediction model of rail corrugation [41]. In addition to the validation procedure of the prediction model of rail corrugation reported in the literature [22,23], the author believes that more validation procedures are needed. In the past, most validation works have been focused on corrugation on the low rail of tightly curved tracks. Since the occurrence tendency of corrugation on the low rail of tightly curved tracks is very close to $100 \%$, the actual measured corrugation may be accidentally consistent with the model prediction result. Many researchers have reported that their models have been validated by comparing the actual measured corrugation occurring on the low rail of tightly curved tracks with the model prediction result. However, most of the validated models have not included the effect of the radius of curved tracks. In other words, when using the common parameters of vehicles and tracks except for the radius of curved tracks as an input, these models can predict corrugation without difficulty. That is to say, the occurrence probability of rail corrugation predicted by these models is close to $100 \%$. Obviously, this prediction result is not different from the afore-mentioned CD phenomenon of rail corrugation. In China, a rail of $60 \mathrm{~kg} / \mathrm{m}$ and worn-type wheel tread profile is used in both the railway main-lines and metro lines. The occurrence probability of rail corrugation on the rails on the railway main-lines is less than 1-3\%. However, the occurrence probability of rail corrugation on the rails on the metro lines is about $10-30 \%$ or higher. There is a big difference between the actual measured corrugation and model prediction result. Hence, the author proposes using the CD phenomenon of rail corrugation as the benchmark condition for rail corrugation validation in place of using corrugation occurring on the low rail of tightly curved tracks.

For validation of the author's model, parameters of the rail, wheelset, sleeper, and fastener must be given. In the literature, few reports on these parameters have been found. Subsequently, the author has used an author-self measuring corrugation, as shown in Figure 9, as an example in order to introduce the validation work. This corrugation occurred on the low rail of a metro track of radius $350 \mathrm{~m}$ with a superelevation of $120 \mathrm{~mm}$. The rails were supported by Cologne-egg fasteners. The high rail did not suffer from corrugation. The running speed of metro trains is about $50 \mathrm{~km} / \mathrm{h}$. From Figure 9 , it can be seen that the wavelength of rail corrugation is about $45 \mathrm{~mm}$. The corresponding frequency of rail corrugation is about $308.64 \mathrm{~Hz}$. Figure 10 gives a prediction result. From Figure 10 it can be seen that there is an unstable vibration of frequency $321.38 \mathrm{~Hz}$. This prediction result is close to the measured corrugation frequency of $308.64 \mathrm{~Hz}$. The relative error between the predicted and measured results is about $4.1 \%$. 


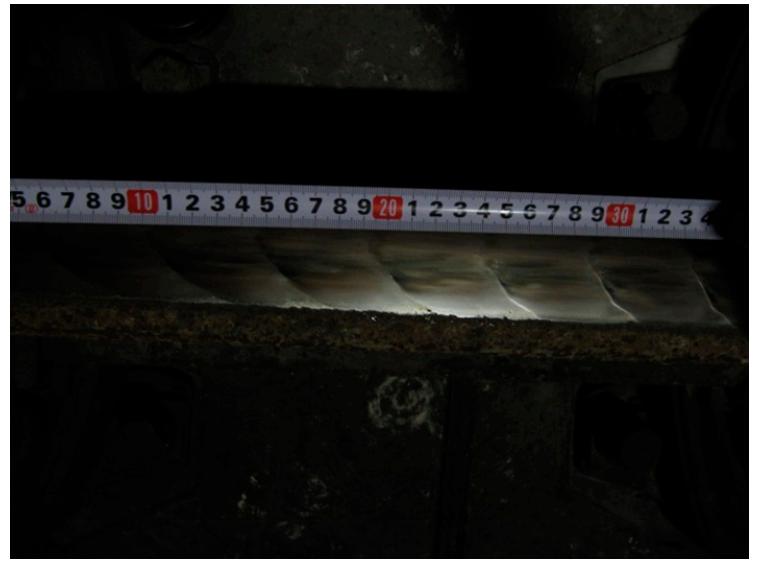

Figure 9. Picture of rail corrugation.

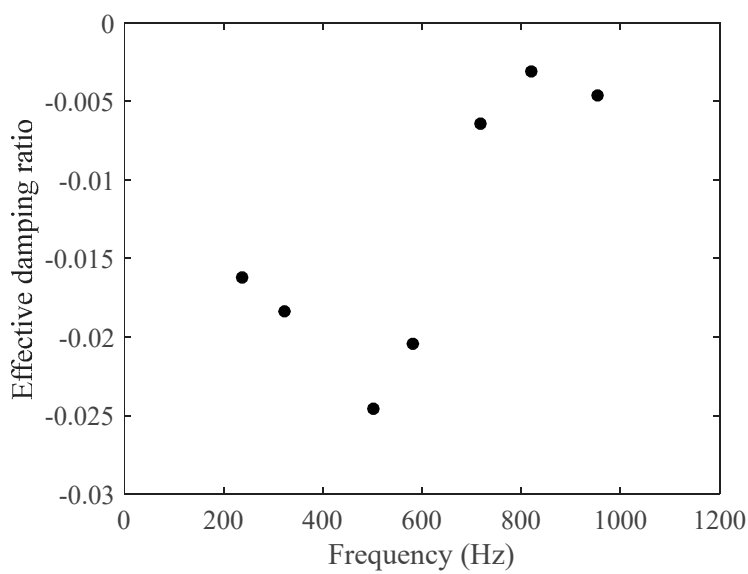

Figure 10. Distribution of unstable vibrations.

\section{Conclusions}

In the present study, the slip of wheels on rails was analyzed and the squealing vibration of the wheelset-track system was investigated, and the correlation between the slip of wheels on rails and rail corrugation was proposed. It was found that the slip of wheels on rails easily causes squealing vibration within the wheelset-track system and that the mode shape of the squealing vibration is very similar to the $\mathrm{CD}$ phenomenon of rail corrugation. The following conclusions can be drawn:

(1) In a tightly curved track, the slip of the wheel of the leading wheelset on the rail always occurs.

(2) When the creep force between the wheel and rail is saturated, the wheelset-track system has a strong occurrence propensity of unstable vibrations.

(3) The unstable vibration of the wheelset-track system is probably a wavelength-fixing mechanism.

(4) The accuracy of the rail corrugation prediction based on the unstable vibrations of wheelset-track systems is found to be $85-90 \%$ or higher.

In the future, the effects of the constraints of the wheelset and rails on rail corrugation need to be studied further. More validation of the self-excited vibration of the wheelset-track system needs to be conducted.

Funding: This research was funded by the National Natural Science Foundation of China (No. 51775461).

Conflicts of Interest: The authors declare no conflict of interest. 


\section{Appendix A}

Main source code:

**

** STEP: apply-force-y

*Step, name=apply-force-y, nlgeom $=$ YES, inc $=1000$

*Static

$0.01,0.2,2 \times 10^{6}, 0.2$

** LOADS

**

**

** STEP: slip

*Step, name=slip, nlgeom $=$ YES, inc $=1000$

*Static

$0.005,0.2,2 \times 10^{6}, 0.2$

*Motion, Translation

wheelset, 3, -65.42

** OUTPUT REQUESTS

${ }^{*}$ Restart, write, overlay, frequency $=1$

** FIELD OUTPUT: F-Output-1

*End Step

**

** STEP: frequency

*Step, name=frequency, nlgeom $=\mathrm{NO}$, perturbation

*Frequency, eigensolver=AMS, normalization=mass, acoustic coupling $=$ off

$2500,0.1,2500$.

** OUTPUT REQUESTS

* Restart, write, frequency $=0$

** FIELD OUTPUT: F-Output-2

${ }^{*}$ Output, field, variable=PRESELECT

*End Step

**

** STEP: complex

*Step, name $=$ complex, nlgeom $=$ YES, perturbation, unsymm $=$ YES

${ }^{*}$ Complex Frequency, friction damping $=\mathrm{NO}$

1800, 5., 1100.,

** OUTPUT REQUESTS

${ }^{*}$ Output, field, variable $=$ PRESELECT

*End Step

\section{References}

1. Grassie, S.L. Rail Corrugation, Chapter 11, Wheel/Rail Interface Handbook; Lewis, R., Olofsson, U., Eds.; CRC Press: Boca Raton, FL, USA, 2009; pp. 349-376.

2. Oostermeijer, K.H. Review on short pitch rail corrugation studies. Wear 2008, 265, 1231-1237. [CrossRef]

3. Sato, Y.; Matsumoto, A.; Knothe, K. Review on rail corrugation studies. Wear 2002, 253, 130-139. [CrossRef]

4. Kinkaid, N.M.; O’Reilly, M.O.; Papadopoulos, P. Automotive disc brake squeal. J. Sound Vib. 2003, 267, 105-166. [CrossRef]

5. Ibrahim, R.A. Friction-induced vibration, chatter, squeal, and chaos. Part 2. Dynamics and modeling. Appl. Mech. Rev. 1994, 47, 227-253. [CrossRef]

6. Guida, D.; Nilvetti, F.; Pappalardo, C.M. Instability induced by dry friction. Int. J. Mech. 2009, 3, 44-51. 
7. Glocker, C.; Cataldi-Spinola, E.; Leine, R.I. Curve squealing of trains: Measurement, modelling and simulation. J. Sound Vib. 2009, 324, 365-386. [CrossRef]

8. Ding, B.; Squicciarini, G.; Thompson, D. Effect of rail dynamics on curve squeal under constant friction conditions. J. Sound Vib. 2019, 442, 183-199. [CrossRef]

9. Kalousek, J.; Johnson, K. An investigation of short pitch wheel and rail corrugations on the Vancouver mass transit system. Proc. Inst. Mech. Eng. Part F J. Rail Rapid Transit 1992, 206, 127-135. [CrossRef]

10. Hempelmann, K.; Knothe, K. An extended linear model for the prediction of short pitch corrugation. Wear 1996, 191, 161-169. [CrossRef]

11. Nielsen, J.C.O.; Lund, N.R.; Johansson, A.; Vernersson, T. Train-Track Interaction and Mechanisms of Irregular Wear on Wheel and Rail Surfaces. Veh. Syst. Dyn. 2003, 40, 43-54. [CrossRef]

12. Gomez, J.; Vadillo, E.G.; Santamaria, J. A comprehensive track model for the improvement of corrugation models. J. Sound Vib. 2006, 293, 522-534. [CrossRef]

13. Meehan, P.A.; Daniel, W.J.T.; Campey, T. Prediction of the growth of wear-type rail corrugation. Wear 2005, 258, 1001-1013. [CrossRef]

14. Wu, T.X.; Thompson, D.J. An investigation into rail corrugation due to micro-slip under multiple wheel/rail interactions. Wear 2005, 258, 1115-1125. [CrossRef]

15. Jin, X.S.; Wen, Z.F.; Wang, K.Y.; Zhou, Z.R.; Liu, Q.Y.; Li, C.H. Three-dimensional train-track model for study of rail corrugation. J. Sound Vib. 2006, 293, 830-855. [CrossRef]

16. Valdivia, A.R. A linear dynamic wear model to explain the initiating mechanism of corrugation. Veh. Syst. Dyn. 1988, 17, 493-496. [CrossRef]

17. Tassilly, E.; Vincent, N. A linear model for the corrugation of rails. J. Sound Vib. 1991, 150, 25-45. [CrossRef]

18. Muller, S. A linear wheel-rail model to investigate stability and corrugation on straight track. Wear 2000, 243, 122-132. [CrossRef]

19. Igeland, A.; Ilias, H. Rail head corrugation growth predictions based on non-linear high frequency vehicle/track interaction. Wear 1997, 213, 90-97. [CrossRef]

20. Torstensson, P.T.; Nielsen, J.C.O. Simulation of dynamic vehicle-track interaction on small radius curves Veh. Syst. Dyn. 2011, 49, 1711-1732. [CrossRef]

21. Sheng, X.; Thompson, D.J.; Jones, C.J.C.; Xie, G. Simulations of roughness initiation and growth on railway rails. J. Sound Vib. 2006, 293, 819-829. [CrossRef]

22. Torstensson, P.T.; Schilke, M. Rail corrugation growth on small radius curves-Measurements and validation of a numerical prediction model. Wear 2013, 303, 381-396. [CrossRef]

23. Hiensch, M.; Nielsen, J.C.O.; Verheijen, E. Rail corrugation in The Netherlands-measurements and simulations. Wear 2002, 253, 140-149. [CrossRef]

24. Tassilly, E.; Vincent, N. Rail corrugations: Analytical model and field tests. Wear 1991, 144, $163-178$. [CrossRef]

25. Diana, G.; Cheli, F.; Bruni, S.; Collina, A. Experimental and numerical investigation on subway short pitch corrugation. Veh. Syst. Dyn. 1998, 29, 234-245. [CrossRef]

26. Batten, R.D.; Bellette, P.A.; Meehan, P.A.; Horwood, R.J.; Daniel, W.J.T. Field and theoretical investigation of the mechanism of corrugation wavelength fixation under speed variation. Wear 2011, 271, 278-286. [CrossRef]

27. Vila, P.; Fayos, J.; Baeza, L. Simulation of the evolution of rail corrugation using a rotating flexible wheelset model. Veh. Syst. Dyn. 2011, 49, 1749-1769. [CrossRef]

28. Baeza, L.; Vila, P.; Xie, G.; Iwnicki, S.D. Prediction of rail corrugation using a rotating flexible wheelset coupled with a flexible track model and a non-Hertzian/non-steady contact model. J. Sound Vib. 2011, 330, 4493-4507. [CrossRef]

29. Liu, S.Q. Study on rail corrugation on metro tracks and its suppression. Railw. Signal. Commun. 2014, 5, 18-19.

30. Brockley, C.A.; Ko, P.L. An investigation of rail corrugation using friction-induced vibration theory. Wear 1988, 128, 99-105. [CrossRef]

31. Suda, Y.; Hanawa, M.; Okumura, M.; Iwasa, T. Study on rail corrugation in sharp curves of commuter line. Wear 2002, 253, 193-198. [CrossRef]

32. Sun, Y.Q.; Simson, S. Wagon-track modelling and parametric study on rail corrugation initiation due to wheel stick-slip process on curved track. Wear 2008, 265, 1193-1201. [CrossRef] 
33. Saulot, A.; Baillet, L. Dynamic finite element simulations for understanding wheel-rail contact oscillatory states occurring under sliding conditions. J. Tribol. 2006, 128, 761-770. [CrossRef]

34. Chen, G.X.; Zhou, Z.R.; Ouyang, H.; Jin, X.S.; Zhu, M.H.; Liu, Q.Y. A finite element study on rail corrugation based on saturated creep force-induced self-excited vibration of a wheelset-track System. J. Sound Vib. 2010, 329, 4643-4655. [CrossRef]

35. Cui, X.L.; Chen, G.X.; Zhao, J.W.; Yan, W.Y.; Ouyang, H.; Zhu, M.H. Field investigation and numerical study of the rail corrugation caused by frictional self-excited vibration. Wear 2017, 376-377, 1919-1929. [CrossRef]

36. Cui, X.L.; Chen, G.X.; Yang, H.G.; Zhang, Q.; Ouyang, H.; Zhu, M.H. Effect of the wheel/rail contact angle and the direction of the saturated creep force on rail corrugation. Wear 2015, 330, 554-562. [CrossRef]

37. Shabana, A.A.; Zaazaa, K.E.; Sugiyama, H. Railroad Vehicle Dynamics: A Computational Approach; CRC Press: Boca Raton, FL, USA, 2007.

38. Pombo, J.; Ambrósio, J.; Silva, M. A new wheel-rail contact model for railway dynamics. Veh. Syst. Dyn. 2007, 45, 165-189. [CrossRef]

39. Pombo, J.C.; Ambrósio, J.A. Application of a wheel-rail contact model to railway dynamics in small radius curved tracks. Multibody Syst. Dyn. 2008, 19, 91-114. [CrossRef]

40. Chen, G.X.; Zhou, Z.R.; Kapsa, P.; Vincent, L. Experimental investigation into squeal under reciprocating sliding. Tribol. Int. 2003, 36, 961-971. [CrossRef]

41. Chen, G.X.; Zhang, S.; Wu, B.W.; Zhao, X.N.; Wen, Z.F.; Ouyang, H.; Zhu, M.H. A comparative study between The field measurement and prediction of rail corrugation. In Proceedings of the 11th International Conference on Contact Mechanics and Wear of Rail/Wheel Systems, Delft, The Netherlands, 24-27 September 2018.

(C) 2020 by the author. Licensee MDPI, Basel, Switzerland. This article is an open access article distributed under the terms and conditions of the Creative Commons Attribution (CC BY) license (http://creativecommons.org/licenses/by/4.0/). 